\title{
Comercio internacional, prosperidad y desigualdad en la globalización
}

Fecha de recepción: 14 de septiembre de 2020

\author{
Leonardo Raffo López* \\ Edwin Arbey Hernández García**
}

Fecha de aprobación: 18 de enero de 2021

Resumen: El propósito de este artículo es hacer una descripción y una reflexión crítica sobre las tendencias del comercio mundial de bienes y servicios y la desigualdad económica durante las últimas décadas en el contexto de la globalización. Para ello se explican algunos procesos clave que han marcado esta etapa del desenvolvimiento del sistema capitalista. A partir de aquí se identifican los principales procesos virtuosos, pero también los problemas económicos relacionados con la desigualdad que han caracterizado la evolución de la economía mundial durante las últimas décadas. El resultado de esta dinámica ha sido la perpetuación de diversos tipos de desigualdades y la permanencia de un gran conjunto de grupos sociales sumidos en la pobreza y atados a territorios generalmente explotados por las garras del capital transnacional, cuyos discursos y cosmovisiones propias terminan siendo invisibilizados por los emisores que se autoproclaman como universales.

Palabras clave: comercio internacional; globalización; capitalismo; desigualdad; crisis económicas.

Clasificación JEL: F13, F15, F63, F68, F11.

Cómo citar este artículo:

Raffo-López, L., \& Hernández-García, E. (2021). Comercio internacional, prosperidad y desigualdad en la globalización. Apuntes del Cenes, 40(71). Págs. 133 - 164 https://doi.org/10.19053/01203053.v40.n71.2021.11736

\footnotetext{
* Magíster en Economía Aplicada. Profesor titular en el Departamento de Economía de la Universidad del Valle. Colombia. Correo: leonardo.raffo@correounivalle.edu.co (i) https://orcid.org/0000-0001-6087-535X Contacto de correspondencia

** Magíster en Economía Aplicada. Profesor asociado en el Departamento de Economía de la Universidad de San Buenaventura. Colombia. Correo: edwinarbeyh@gmail.com (iD https://orcid.org/0000-0002-5919-7659
} 


\title{
International Trade, Prosperity and Inequality in Globalization
}

\begin{abstract}
This paper purpose is to make a description and a critical discussion about some key trends in the world trade of goods and services, and economic inequality during the last decades in the globalization context. With this aim, we explain some key processes underlying this evolving capitalist phase. From there, we point out the main virtuous processes but also economic problems characterizing the evolution of the world economy during the last decades. The result of this dynamic has been the perpetuation of various types of inequalities, and the permanence of a large set of social groups mired in poverty and tied to territories generally exploited by the grasps of transnational capital, whose own discourses and worldviews end up being invisible by issuers who proclaim themselves as universal.
\end{abstract}

Keywords: international trade; globalization; capitalism; inequality; economic crisis. 


\section{INTRODUCCIÓN}

Uno de los fenómenos económicos prominentes del capitalismo contemporáneo ha sido la expansión y profundización sin precedentes del comercio mundial de bienes y servicios. Entre 1970 y 2018 este creció en promedio cerca del $120 \%$ de la producción mundial. Se trataba de una tendencia sostenida, a excepción de lo ocurrido entre el año 2008 y el 2009 como resultado de la gran recesión ${ }^{1}$. Así, entre el año 2000 y 2018 el comercio mundial de mercancías creció a una tasa promedio anual real del $4.1 \%$. Tanto es así que durante la década 2008-2018 el valor de las exportaciones a precios contantes fue casi tres veces el nivel de la década de los noventa y cinco veces el nivel de la década de los ochenta (cálculos propios con base en datos del Banco Mundial).

Pero, no solo se trataba de cambios cuantitativos en los flujos comerciales, también se produjeron transformacio- nes cualitativas que modificaron las dimensiones y el alcance del comercio internacional. La producción de muchos bienes y servicios dejó de ser exclusiva de países individuales para adquirir un carácter transnacional (OMC, 2013, 2014; Riad et al., 2012). Esto constituyó un cambio fundamental en las tecnologías de producción de muchas actividades económicas en diversas partes del mundo, caracterizado por la profundización en los niveles de especialización vertical de países, regiones y unidades económicas. Con esto adquirieron un papel central las cadenas de valor internacionales; pero, al mismo tiempo, se desarrollaron transformaciones de fondo en los procesos de acumulación de capital en todo el mundo.

En el mundo contemporáneo un gran número de espacios de intercambio pasaron a ser mercados globales. El avance de los medios de comunicación -y en particular de Internet- permitió

1 Como resultado de la crisis económica y financiera desatada a finales del año 2008 , la tasa de crecimiento real anual del comercio mundial de bienes y servicios pasó de $6.5 \%$ en 2007 a $2.9 \%$ en 2008, pero la contracción del $10.1 \%$ en 2009 no había tenido precedentes históricos. A pesar de esto, en el año 2010 el comercio de mercancías se recuperó rápidamente alcanzando una tasa de crecimiento de $11.6 \%$, la más alta hasta la fecha. Durante los años siguientes (2012-2018), el comercio de mercancías creció a tasas estables pero muy inferiores a la tasa promedio del $4.1 \%$ correspondiente al periodo 2000-2018 (cálculos propios con base en datos del Banco Mundial). 
incrementar notoriamente los flujos comerciales entre los países. Como resultado, en todo el mundo el comercio internacional de servicios creció vertiginosamente durante las décadas anteriores, a tasas aún mayores que las de su propia producción (OMC, 2010, 2013). De hecho, solamente durante el periodo 1997-2007 las exportaciones de servicios en los países en desarrollo se triplicaron (Mishra et al., 2011). La posibilidad de comerciar servicios sin enfrentar barreras físicas ha desempeñado un papel crucial en este proceso (Garavito-Acosta et al., 2019), que además tiene fuertes implicaciones: la economía inmaterial ha ganado terreno frente a la economía industrial tradicional (Preciado, 2020).

Durante las últimas décadas también se presentó una considerable expansión del volumen y variedad de recursos naturales transados en todo el mundo (OMC, 2010), jalonada por las crecientes demandas de las grandes potencias económicas. El problema es que los países con mayores dotaciones de recursos naturales sostienen tasas de explotación muy elevadas que son insostenibles a largo plazo (Pérez-Rincón, 2007). Esto último revela que los procesos de globalización llevaron a que muchos países se especializaran en mayor medida de acuerdo con sus ventajas comparativas. En general, esto favorece el incremento de la producción global de bienes y servicios a corto y medio plazos, pero a largo plazo puede llegar a comprome- ter el crecimiento sostenido e incluso el desarrollo sostenible de los países que se especializan en sectores que no son dinámicos, en especial cuando las ganancias y los costos asociados al comercio -incluyendo sus costos ecológicos- se distribuyen de forma muy desigual entre los socios comerciales.

Pero todas estas dinámicas productivas y comerciales coincidieron con el desenvolvimiento de una serie de dinámicas distributivas que han llevado al empobrecimiento y deterioro de las condiciones laborales de amplios sectores de las sociedades, tanto en las economías más avanzadas, como en los países emergentes y los menos avanzados.

El objetivo principal de este artículo es hacer una descripción y una reflexión crítica sobre las tendencias del comercio mundial de bienes y servicios y la desigualdad económica durante las últimas décadas en el contexto de la globalización.

La hipótesis de partida es que durante las últimas décadas, con el vertiginoso crecimiento del comercio internacional, se ha desarrollado una serie de procesos virtuosos que han sido fuente de prosperidad para muchas economías, pero, al mismo tiempo, muchos individuos, grupos sociales y sectores económicos se han afectado negativamente en términos económicos y sociales, siendo una clara señal de esta dinámica distributiva la persistencia de altos niveles de 
desigualdad interpersonal global y el incremento de la desigualdad en el interior de los países (Lakner \& Milanovic, 2013, 2015; Bourguignon, 2015).

Cabe de entrada advertir que este artículo no se propone examinar las relaciones de causalidad que pueden existir entre la globalización -y en concreto los procesos de apertura y expansión del comercio ligados a esta- y las tendencias en la distribución de la renta y la riqueza que se han manifestado durante las últimas décadas. En cambio, lo que se pretende es principalmente describir de forma sintética algunas tendencias del comercio y la desigualdad económica, así como reflexionar críticamente sobre ellas sin llegar a afirmar que las primeras son causa de las segundas 3 .

El artículo, aparte de esta introducción, se ha organizado de la siguiente manera. En la primera sección se explican dos procesos clave que han marcado la globalización. En la segunda se identifican los principales procesos virtuosos y problemas económicos que han marcado la evolución de la economía mundial durante las últimas décadas. Por último, se plantea una reflexión final.

\section{DOS PROCESOS CLAVE EN LA GLOBALIZACIÓN}

Antes de responder las preguntas planteadas es necesario entender en qué consisten los procesos de globalización económica que han caracterizado el desenvolvimiento del comercio mundial desde 1980. Estos procesos subyacen en todos los fenómenos mencionados atrás y son el resultado de un estado de avance del capitalismo mundial. La globalización económica puede concebirse como un proceso progresivo de transnacionalización del capital en el que se desarrolla la libre movilidad de capitales y con ello el crecimiento de los mercados financieros y de grandes corporaciones multinacionales de forma más o menos independiente del desarrollo de las economías nacionales (Soros, 2002). El resultado de este proceso es el crecimiento vertiginoso del comercio de bienes y servicios a nivel internacional, al mismo tiempo que se presentaba un incremento en las transacciones internacionales de otros factores de producción -aparte del capital- como los recursos naturales y el conocimiento. En contraste, en general no sucede lo mismo con la mano de obra (Ravallion, 2018), que continúa presentando un gran número de obstáculos legales, políticos, culturales y técnicos para una mayor movilidad internacional. Una excepción a esta regla es la movilidad internacio-

2 Ver más adelante una definición de este concepto.

3 El estudio de las relaciones de causalidad existentes entre los dos tipos de procesos señalados constituye un problema de investigación promisorio. Para tener una idea del calibre e importancia de esa línea de investigación, que no se aborda en el presente artículo, ver Meschi y Vivarelli (2009), Harrison et al. (2011), Helpman et al. (2017), Bourguignon (2015), Ravallion (2018), entre otros. 
nal creciente que ha adquirido la mano de obra con los más altos niveles de calificación (Bourguignon, 2015).

En la base de las transformaciones económicas y tecnológicas ocurridas está la emergencia de verdaderos circuitos de capital transnacional y la configuración de nuevos sistemas de producción y financieros globales, cuyo funcionamiento depende de la actividad de una nueva clase capitalista transnacional comandada por una élite directiva (managerial elite) (Robinson, 2011). Como agudamente señala este autor, "las élites globales emergentes y los capitalistas transnacionales dieron lugar al desmantelamiento de los distintos modelos asociados al capitalismo nacional corporativo y construyeron un nuevo régimen 'flexible' global de acumulación" (Robinson, 2011, p. 353)4.

Siguiendo principalmente a Robinson (2011), Harvey (2008), UNCTAD (2013) y Bourguignon (2015), dos procesos socioeconómicos fueron claves para comprender la globalización: 1) una nueva relación capital/trabajo caracterizada por la desregulación, la informalización y la flexibilización del trabajo (Robinson, 2011; Harvey, 2008; Bourguignon, 2015). 2) El rol prominente de un sector financiero pobremente regulado (UNCTAD, 2010; Malinowitz, 2010).

\section{Una nueva relación capital/trabajo}

La configuración de una nueva relación capital/trabajo se desarrolló en parte como consecuencia de la implementación de modelos neoliberales en la mayor parte de los países. Es el factor clave para entender la dinámica distributiva durante las últimas décadas 5 . Como resultado de la implementación sistemática de políticas de flexibilización laborales y desregulación de los mercados de trabajo, la proporción del ingreso salarial en la producción mundial ha exhibido una tendencia decreciente (UNCTAD, 2010; Bourguignon, 2015). En consecuencia, y en oposición a lo ocurrido durante los años setenta, en promedio durante las décadas posteriores y parte de la década pasada, los márgenes de ganancias de las firmas tendieron a crecer y dieron lugar a un incremento en la tasa de ganancia de la economía (Duménil \& Lévy, 2007). El problema de este proceso es que "la tendencia de las compañías a buscar ganancias a través de la explotación de los diferenciales de salarios, en vez de hacerlo a través de la innovación y la inversión, ha generado beneficios limitados para al resto de la sociedad" (UNCTAD, 2010, p. 15)6.

De hecho, el descenso progresivo de los ingresos salariales en la producción mundial ha conducido a un debilitamiento sistemático de la

\footnotetext{
$4 \quad$ La traducción es propia.

5 Este punto se tratará más ampliamente en la próxima sección.

6 La traducción es propia.
} 
demanda agregada, que es especialmente notorio en las economías más avanzadas. Esta es la principal causa de la inestabilidad creciente de la economía mundial a partir de la primera década de este siglo: como los ingresos salariales constituyen la fuente de ingresos más grande, "alrededor de dos tercios en los países desarrollados" (UNCTAD, 2010, pp. 14-15), su reducción en términos relativos conduce inevitablemente a un debilitamiento de la demanda agregada de las economías. Así, el descenso progresivo de la proporción de la demanda interna en la producción nacional de los países, especialmente en el caso de los países avanzados, ha llevado a que las economías sean más inestables frente a los choques externos y los cambios súbitos en la inversión -externa e interna- causados por revisiones en las expectativas, y a que los equilibrios a corto plazo entre el ahorro y la inversión sean menos estables. Al presentarse un debilitamiento sistemático de la demanda agregada en muchos países, se crea una tendencia sistemática al desempleo involuntario, en niveles de demanda efectiva por debajo del pleno empleo (Keynes, 1973). El resultado de todo esto es una mayor propensión a la crisis de las economías nacionales y, por ende, de la economía global en su conjunto.

\section{El rol prominente de un sector finan- ciero pobremente regulado}

Por otra parte, el rol prominente de un sector financiero pobremente regulado ha consolidado el funcionamiento expansivo de circuitos de capital financiero transnacional al margen de las políticas de estabilización implementadas en la mayor parte de los países en distintas coyunturas a lo largo de las últimas décadas. A medida que se desarrollaban y profundizaban los mercados financieros en las economías emergentes y las menos avanzadas, se creaban las bases para la expansión del capitalismo global, pero al mismo tiempo, crecía la volatilidad de todos los mercados a nivel nacional e internacional, al estar cada vez más interconectados y teniendo a su disposición tecnologías de información y transmisión cada vez más eficientes. Con las transformaciones ocurridas, el sistema financiero, en cabeza de los grandes capitalistas financieros y los administradores de los bancos, bolsas de valores, fondos de inversión, fondos de pensiones y cesantías, de seguros, etc., adquirió la capacidad de administrar las crisis según su propio interés (Duménil \& Lévy, 2007) y alcanzó un poderío económico sin precedentes que le garantizaba su sostenibilidad y favorecimiento, incluso en épocas de recesión.

La importancia creciente del sector financiero llevó a que el capital financiero ganara cada vez más espacios, así como poder económico y político. Así, se alude a la financiarización como 
una fase capitalista caracterizada por la búsqueda de beneficios a través de los canales financieros (Malinowitz, 2010). Con esto se profundizan los mercados financieros y emergen nuevos mecanismos de financiación útiles para los procesos de producción de las empresas, especialmente para aquellas que logran insertarse en los circuitos internacionales del capital, en cabeza de las multinacionales. Pero, al mismo tiempo, crecen los mercados especulativos y con ello los riesgos de colapsos bursátiles generalmente precedidos de fuertes auges o burbujas. De hecho, ese fue el caso de la gran recesión desatada en el 2008. Primero en Estados Unidos y luego en Europa, el crash financiero y la crisis económica estuvieron precedidos por el crecimiento de grandes burbujas inmobiliarias, que finalmente reventaron.

\section{TENDENCIAS DEL COMER- CIO INTERNACIONAL Y LA DESIGUALDAD}

Durante las cuatro décadas anteriores se desarrollaron tendencias del comercio internacional y la desigualdad de la renta y la riqueza que marcaron la evolución de la economía mundial. Una parte de estas tendencias corresponde a procesos virtuosos que han beneficiado a la mayor parte de las economías del globo $\mathrm{y}$, en consecuencia, han sido ventajosos para la prosperidad y el desa- rrollo económico y social en general. No obstante, la otra parte constituye serias problemáticas que han puesto en duda el bienestar de grandes comunidades en diferentes lugares del globo e, incluso, cuestiona el futuro del capitalismo -tal como se desenvuelve en la actualidady la propia humanidad.

\section{Algunos procesos virtuosos en la globalización}

En primer lugar, algunos países en desarrollo, en especial las economías emergentes del G-207, alcanzaron tasas de crecimiento asombrosas. El repunte que tuvieron los precios de los bienes primarios y del petróleo durante la mayor parte de la primera década del siglo XXI fue decisivo en el desempeño de aquellas economías, debido a la alta proporción que representa esta clase de bienes en sus exportaciones totales (OMC, 2014).

Como se puede observar en la Figura 1, la participación de las economías en desarrollo en la producción mundial aumentó del $18 \%$ al $28 \%$ entre 1970 y el año 2000, y del $28 \%$ al $41 \%$ entre el año 2000 y 2018, es decir, que creció más los primeros 18 años del siglo XXI que los últimos 30 años del siglo XX. Por otra parte, la participación de esos países en el comercio mundial se incrementó del $22 \%$ al $30 \%$ entre 1970

$7 \quad$ Dejando de lado a la Unión Europea y a los ocho países más avanzados del G8 (Alemania, Canadá, Estados Unidos, Francia, Italia, Japón, Reino Unido y la Federación Rusa), pertenecen a este grupo los siguientes países emergentes: Arabia Saudita, Argentina, Australia, Brasil, China, la India, Indonesia, México, la República de Corea, Sudáfrica, Turquía y la Unión Europea. 
y el año 2000, y aumentó del $30 \%$ al $36 \%$ entre el año 2000 y 2018 . Estas tendencias fueron jalonadas por países como China, la Federación Rusa y la India, que tuvieron tasas de crecimiento del PIB per cápita real promedio anual entre el año 2000 y el 2018 del $8.5 \%$, el $3.8 \%$ y el $5.2 \%$, respectivamente; esto a pesar de los impactos negativos que tuvo la Gran Recesión sobre el crecimiento económico mundial.

Cabe agregar que mientras China ha basado su crecimiento en una boyante dinámica del sector manufacturero, la India lo ha jalonado en mayor medida por un vertiginoso crecimiento del sector servicios (Mishra et al., 2011).

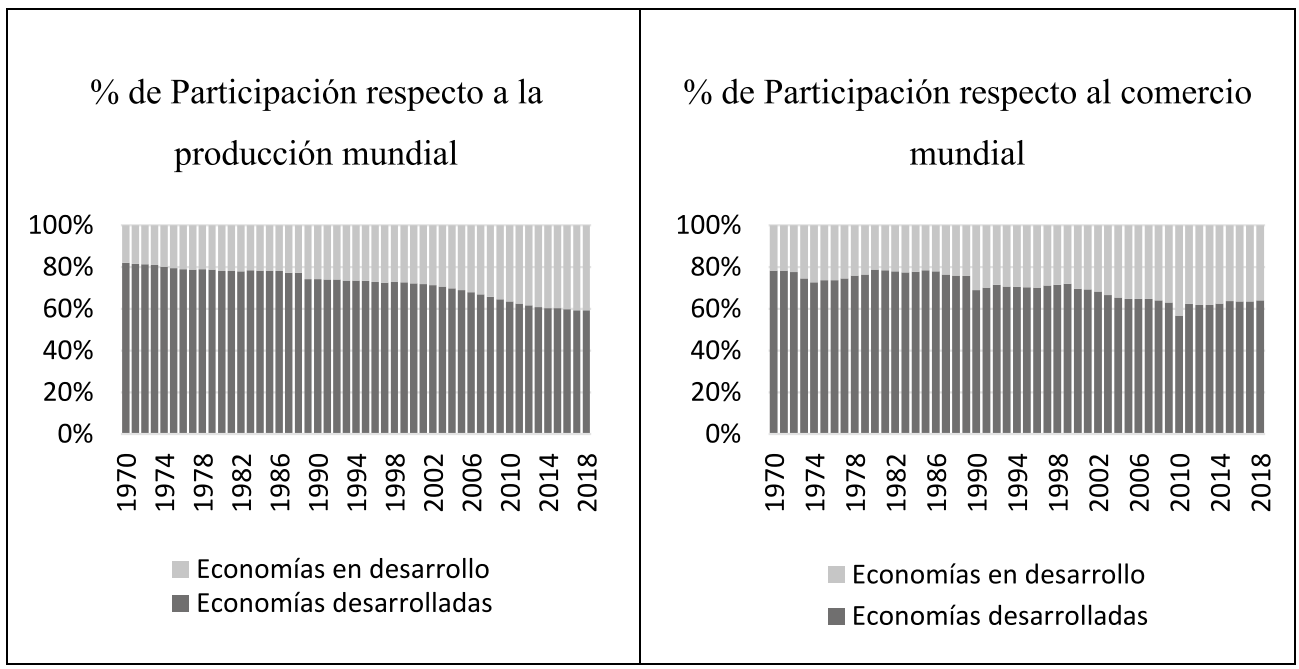

Figura 1. Participación de las economías en la producción mundial.

Fuente: cálculos propios con base en datos del Banco Mundial.

Por su parte, como se observa en la Figura 2, las economías emergentes de China, India y la Federación Rusa mantuvieron tendencias crecientes en sus tasas de crecimiento del PIB real $\mathrm{y}$ en algunos casos sobresalientes, muy por encima del conjunto de los países desarrollados. Según Riad et al. (2012), como resultado de este proceso, Estados Unidos ha perdido parte de su hegemonía económica y comercial con respecto a las economías emergentes del G20. Desde la primera década del siglo XXI China pasó a ser el segundo más grande socio comercial después de Estados Unidos, por encima de países como Alemania y Japón. Aparte de su rápido crecimiento, sus exportaciones adquirieron un patrón más diversificado. 


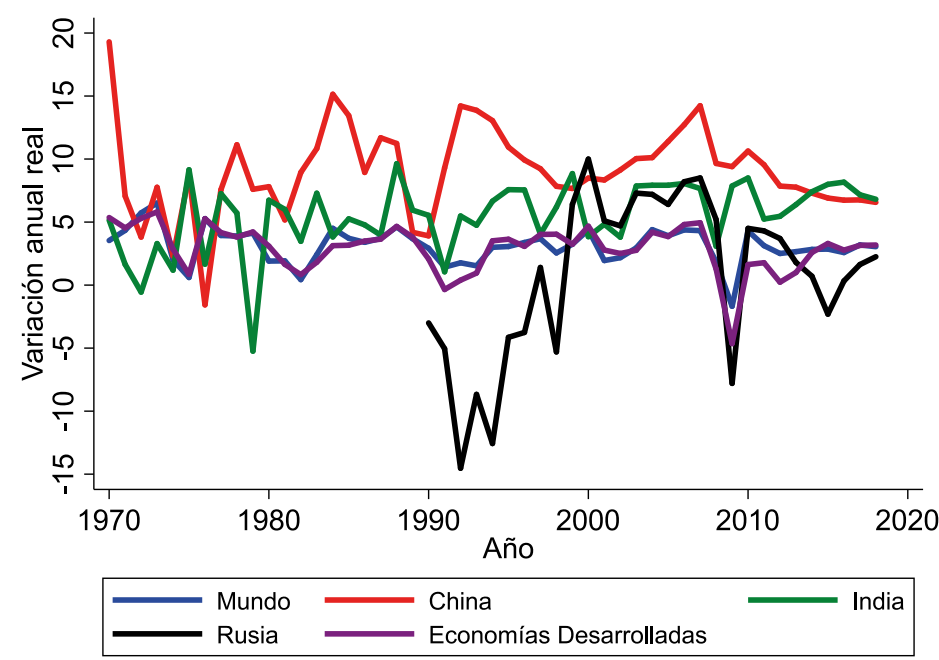

Figura 2. Tasa de crecimiento del PIB anual real.

Fuente: cálculos propios con base en datos del Banco Mundial.

En segundo lugar, en buena medida como consecuencia de lo anterior, durante los primeros diez años del siglo XXI mejoró la distribución del ingreso con relación a los niveles de ingreso per cápita de los países $(\mathrm{OMC}$, 2014; Riad et al., 2012) y, en particular, mejoró tanto la llamada desigualdad internacional no ponderada como la desigualdad internacional ponderada por la población. La desigualdad internacional no ponderada corresponde a la desigualdad en los niveles de ingreso per cápita entre los países del mundo (Milanovic, 2005; Lakner \& Milanovic, 2013, 2015). Entre tanto, la desigualdad internacional ponderada por la población o desigualdad entre paises hace referencia a la desigualdad entre las personas asignándole a cada una el ingreso per cápita de su lugar de residencia (Milanovic, 2005; Lakner \& Milanovic, 2013, 2015; Anand \& Segal, 2008). Esta última mide la desigualdad entre los niveles de ingreso per cápita de los países ponderando a cada uno de acuerdo con su población.

No obstante, Bourguignon (2011) encontró evidencia de que la desigualdad internacional no ponderada continuó incrementándose entre el año 1989 y el año 2006 (Bourguignon, 2011; Lakner \& Milanovic, 2013, 2015). Pero, en términos generales, la desigualad entre países ha tendido a mejorar, sobre todo durante los últimos años, pero principalmente a causa del repunte de economías emergentes con altas tasas de crecimiento como China, India y Brasil. 
Prueba de lo anterior es que la distribución de los países de acuerdo con el promedio de sus rentas per cápita reales en paridad del poder adquisitivo (PPA) ponderado por la población -según su función de densidad kernel-, se desplazó considerablemente a la derecha para el año 2018 con respecto a los años 1990, 2000 y 2011. Esta pasó de ser una distribución aproximadamente bimodal con dos crestas relativamente distantes entre sí para el año de 1990 a una distribución trimodal con un menor nivel de dispersión y distancia entre las crestas para el año 2018, lo que significa que los ingresos per cápita de los países crecieron a la vez que convergieron entre sí. La Figura 3 ilustra esto con base en información del Banco Mundial.

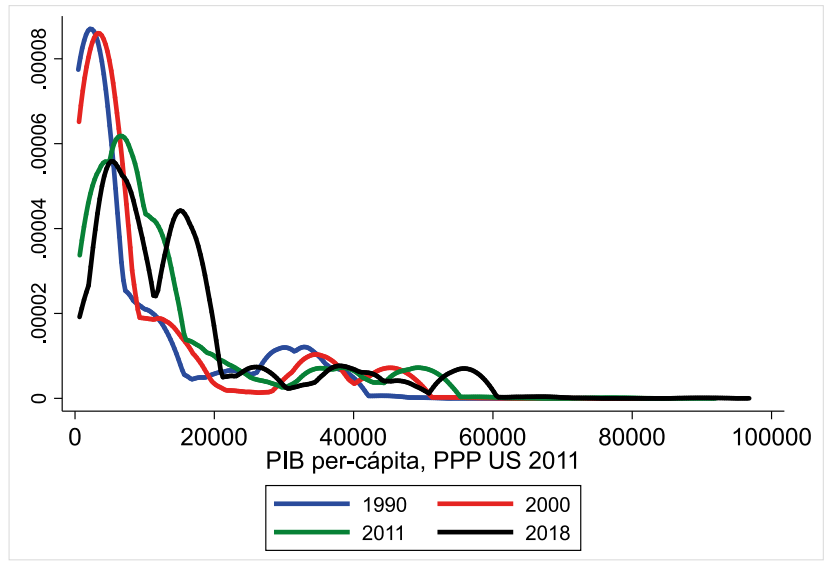

Figura 3. Función de densidad kernel para el PIB per cápita real en PPA en 215 países

Fuente: cálculos propios con base en datos del Banco Mundial.

¿Qué explica esta tendencia? La dinámica distributiva de las últimas cuatro décadas ha estado marcada por la influencia de una serie de fuerzas convergentes, pero también por un conjunto de fuerzas divergentes que actúan en sentido contrario. Las principales fuerzas convergentes son la difusión del conocimiento y las destrezas (Piketty, 2014). Entre tanto, un conjunto de fuerzas divergentes impulsadas por la persistencia de altas tasas de retorno del capital en relación con la tasa de crecimiento de la economía, garantizan la constante acumulación y concentración de la riqueza en manos de la clase capitalista y, al mismo tiempo, la reducción de los ingresos salariales como proporción de la producción nacional (Piketty, 2014). A esto se suma que "los generadores de ingresos más altos se separan rápidamente del resto por un margen 
muy amplio (p. 23)"8. Lo interesante es que la reducción en la desigualdad internacional no ponderada y la desigualdad internacional ponderada por la población se explica en buena medida por las fuerzas convergentes a las que hace alusión Piketty (2014). La siguiente cita de Piketty soporta este argumento:

Knowledge and skill diffusion are the key to overall productivity growth as well as the reduction of inequality both within and between countries. We see this at present in the advances made by a number of previously poor countries led by China. The emergent economies are now in the process of catching up with the advanced ones. By adopting the modes of production of the rich countries and acquiring skills comparable to those found elsewhere, the less developed countries have leapt forward in productivity and increase their national incomes. (Piketty, 2013, p. 21)

El anterior pasaje deja claro que Piketty considera que el principal impacto de los procesos convergentes se da sobre la distribución del ingreso entre los países, o sea, sobre la desigualdad internacional no ponderada y la desigualdad internacional ponderada por la población. ¿Pero cuáles fuerzas han predominado durante las últimas décadas?, ¿las convergentes? ¿o las divergentes? La hipótesis de Piketty (2014) es que ha predominado el segundo conjunto de fuerzas. Retomaremos la discusión sobre las dinámicas distributivas en el siguiente apartado.

En tercer lugar, a la par de lo anterior, a largo plazo el volumen de comercio con respecto al PIB se ha incrementado en la forma de mayores volúmenes de comercio intraindustrial en sectores productivos con rendimientos crecientes a escala que elaboran bienes diferenciados. Así es como a través del cálculo del índice de Grubel y Lloyd a 4 dígitos y controlando sesgo geográfico para 87 países9, para el periodo 1980 y 2016 (Figura 4) se puede observar una tendencia creciente de los flujos de doble vía o comercio intraindustrial, tanto para las economías desarrolladas como para las economías en desarrollo. Asimismo, se puede ver que la tendencia del comercio intraindustrial sigue la tendencia creciente del comercio mundial de bienes y servicios y el grado de apertura comercial como participación de la producción mundial; no obstante, la brecha permanente entre las tendencias del comercio intraindustrial y el grado de apertura económica mundial, después del año 2000 correspondió tanto al auge de las materias primas, como al incremento sostenido de los precios del petróleo y los metales, fruto de las demandas de las economías emergentes como China e India.

\footnotetext{
$8 \quad$ La traducción es propia.

9 Los cálculos del comercio intraindustrial son menores en este trabajo, porque se superan los problemas de sesgo geográfico y sesgo por agregación, que normalmente otros trabajos de investigación calculan a dos dígitos y sin tener en cuenta el sesgo geográfico. Esto ha sido evidenciado por Fontagné y Freudenberg (1997), Moreno y Posada (2007) y recientemente por Hernández (2017).
} 


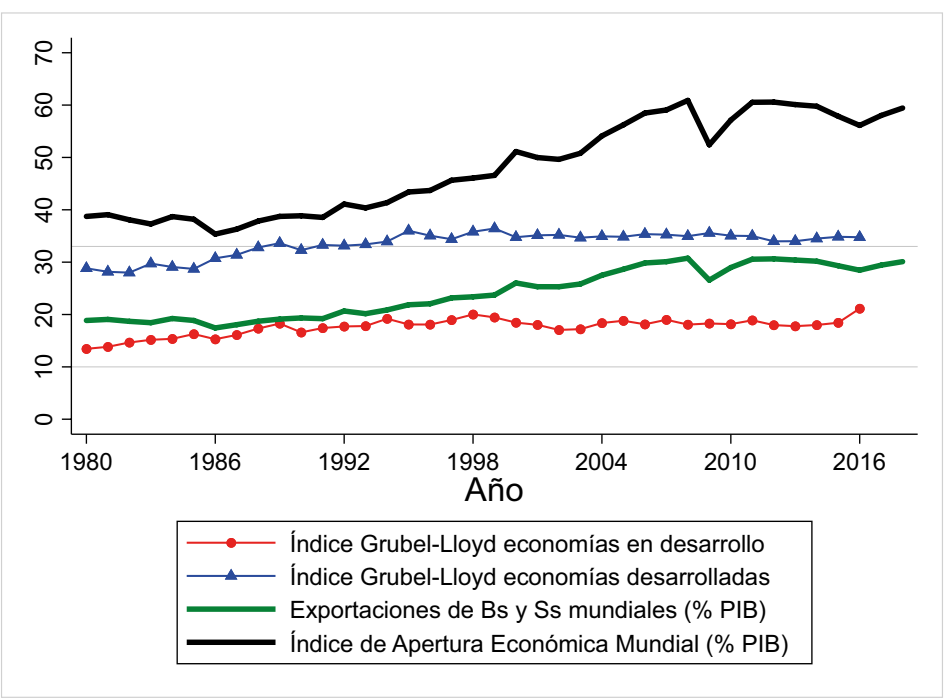

Figura 4. Comercio intraindustrial, exportaciones y grado de apertura comercial mundial.

Fuente: cálculos propios con base en datos del Banco Mundial y COMTRADE.

La mayor integración económica y la consecuente expansión de la escala de producción en esta clase de actividades económicas traen como consecuencia la presencia de costos medios decrecientes $\mathrm{y}$, por ende, descensos en los precios de mercado. La existencia de este tipo de círculos virtuosos de progreso social fue reconocida siglos atrás por Adam Smith: la ampliación del tamaño del mercado permite la profundización de la división del trabajo, jalonando incrementos en la productividad y, con ello, generando un mayor progreso social (Smith, 1981). El bien conocido resultado es un incremento del bienestar económico de los consumidores, por tres razones diferentes: por una parte, la ampliación de la escala de producción en sectores con diferenciación horizontal permite a los consumidores disfrutar de una mayor variedad de mercancías, lo que les posibilitaría alcanzar mayores niveles de satisfacción aun a sus niveles de ingresos reales iniciales. Por otra parte, la baja de los precios que se genera al crecer la escala de producción en presencia de costos medios decrecientes implica un incremento de su renta real y su poder adquisitivo (Krugman, 1979, 1981). En tercer lugar, porque el incremento del comercio intraindustrial trae consigo transiciones suaves dentro de las ocupaciones en el mercado laboral, de tal forma que los costos de ajuste son menores, particularmente dentro de la categoría del comercio intraindustrial horizontal (Hernández \& Raffo, 2019).

Así, la presencia de economías de escala y tecnologías de punta permite a los países explotar las ventajas competitivas de 
sectores productivos que generalmente pertenecen al sector industrial o a franjas terciarias altamente intensivas en tecnología y capital humano.

En cuarto lugar, la estructura de las exportaciones de los países emergentes ha tendido a converger a la de las economías avanzadas, lo que en parte refleja el crecimiento de las cadenas de suministro globales. Por ejemplo, se puede observar en la Figura 5 Panel A que la participación de las exportaciones de medio y alto contenido tecnológico en las exportaciones totales de manufacturas de algunos países emergentes como China, India y México crecieron considerablemente para el periodo 1990-2017, y aunque no tan intensamente, pero sí con una leve tendencia creciente, las de Brasil. Mientras que países avanzados como Estados Unidos y Japón presentaron tendencias decrecientes en la misma variable. Asimismo, en Europa (Figura 5 Panel B) la intensidad tecnológica de las exportaciones se ha trasladado de Europa Occidental a Europa del Este, en particular a países como la República Checa, Hungría y Polonia (Riad et al., 2012). En el Panel B se pueden ver las tendencias crecientes e importantes para estos países de Europa del Este, pasando de una participación de las exportaciones de bienes de media y alta tecnología en cada uno de esos países alrededor del $40 \%$ para el año 1990, al $70 \%$ para República Checa, 76 \% para Hungría y $55 \%$ para Polonia en el año 2017.

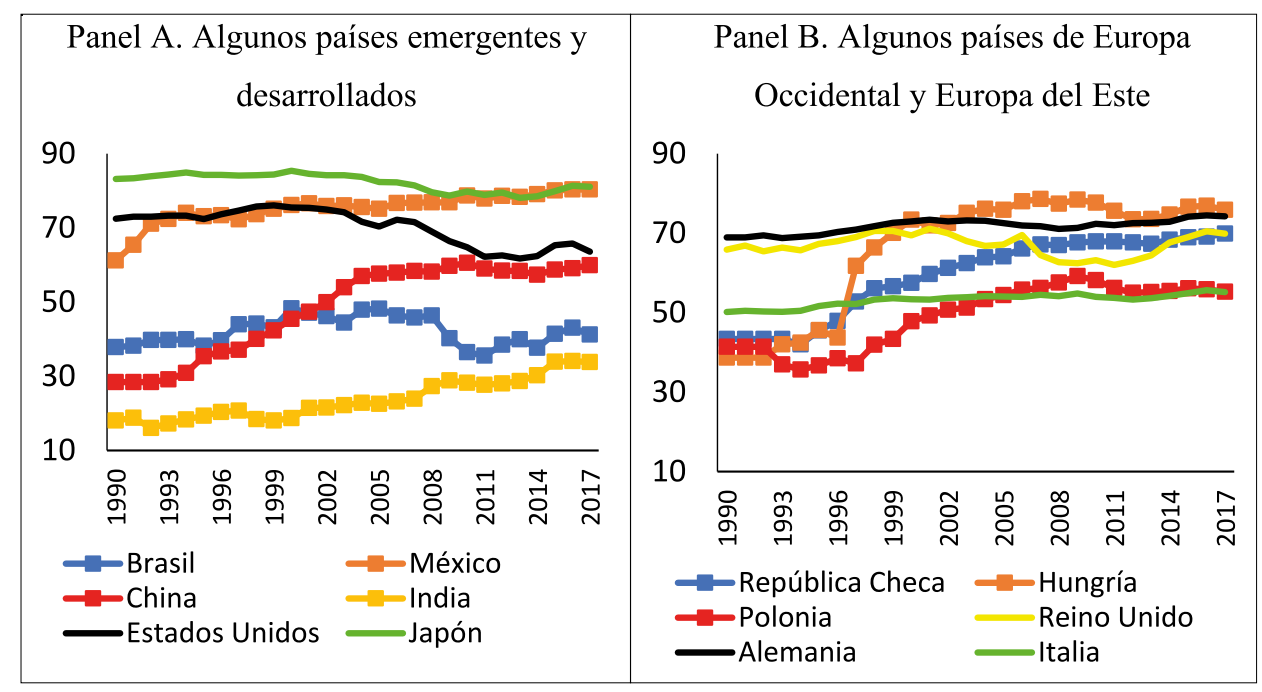

Figura 5. Exportaciones de bienes de media y alta tecnología (porcentaje exportaciones manufactureras)

Fuente: cálculos propios con base en datos del Banco Mundial. 
Esta tendencia se ha reforzado por la creciente implementación de procesos de offshoring por parte de empresas multinacionales de los países más avanzados en el territorio de países menos avanzados con mano de obra, materias primas y recursos naturales relativamente abundantes y baratos. El offshoring se ha asociado usualmente a bienes intermedios manufacturados, pero "en las últimas décadas se ha incrementado en el sector servicios, ya no sólo como una forma de disminuir costos, sino de aprovechar ventajas de tecnología, conocimiento y ubicación geográfica” (Tamayo, 2015, p. 178).

Como afirman de manera precisa Romero y Vera-Colina, esto representa un cambio radical en la estructura organizativa de las empresas:

En este nuevo contexto, el viejo esquema de la gran empresa que administra todo el proceso desde su casa matriz en el país de origen es reemplazado por la creación de empresas filiales en diferentes países alrededor del mundo, lo que permite que se establezca un creciente intercambio de bienes $y$ servicios intrafirma, donde el producto final es el resultado del ensamblaje de partes elaboradas al mismo tiempo en diferentes lugares geográficos y pierde, aparentemente, su made in. (Romero \& Vera-Colina, 2012, pp. 53-54)

Así pues, es evidente que la globalización y el incremento de las transacciones internacionales han ido de la mano del incremento de la producción y el número de mercancías disponibles a nivel internacional. La evidencia reciente corrobora la idea de que el comercio internacional no es un juego de suma cero, sino un juego de suma positiva para todos los países. ¿Pero realmente lo es siempre para todos los agentes que participan en él? En el siguiente apartado se hacen algunas reflexiones en esa dirección.

\section{Algunos problemas en la globalización}

Más allá de los procesos descritos en el numeral anterior, la globalización ha evolucionado de la mano de una serie de problemáticas multidimensionales y complejas, algunas de las cuales paradójicamente no han sido estudiadas con suficiente atención y amplitud ontológica por parte los investigadores económicos. En cambio, desde otras disciplinas sociales, como la sociología, la antropología y la geografía, se han propuesto otros conceptos y esquemas analíticos para estudiarlas. Algunas de las ideas que se exponen a continuación han sido examinadas desde estas perspectivas. Estas proporcionan una visión crítica que va más allá de las teorías e hipótesis que durante décadas han enarbolado los economistas ortodoxos para poder concebir la globalización como una "etapa natural, automática e irreversible [...] del desarrollo (Pérez, 2018, p. 257)", y así, en consecuencia con esta visión, fomentar el "libre comercio" y los procesos de integración económica alrededor del globo, dejando de lado 
los procesos que se tejen localmente en diversos lugares del planeta a la par de los procesos globales.

En primer lugar, no es cierto que el comercio internacional sea un juego en el que todos sus participantes en diferentes niveles (nacionales, regionales, o locales) ganen siempre. En el contexto económico actual, caracterizado por la presencia de mercados competitivos en algunos sectores económicos, pero también por mercados con competencia imperfecta en otros, el balance global del comercio para los países generalmente es positivo, aun cuando muchos individuos, grupos sociales y sectores económicos en su interior pierdan al realizar determinadas transacciones comerciales de forma sistemática. A esto se suma que la influencia de las políticas comerciales aplicadas por los gobiernos -en especial las de los más poderosos- sigue siendo un factor determinante de los volúmenes de exportaciones e importaciones de los países, de sus términos de intercambio y de la manera como se distribuyen las ganancias comerciales entre ellos.

Por ejemplo, en los países más avanzados es frecuente el sostenimiento de poderosos sistemas de subsidios a sectores estratégicos como el agrícola (Garay et al., 2006; Paul, 2006).
En cambio, en algunos casos en los países menos avanzados o emergentes, en vez de implementarse subsidios a sectores estratégicos o dinámicos - por ejemplo, sectores de manufacturas o de servicios intensivos en tecnología y capital humano, o el propio sector agrícola-, se sostienen altos aranceles y medidas no arancelarias a las importaciones en general, los cuales terminan incrementando el precio final de los bienes domésticos que usan bienes de capital e insumos importados. El resultado es la menor competitividad de los bienes nacionales en estos países y una reducción de sus exportaciones (Garavito-Acosta et al., 2020), así como la obtención de menores ganancias relativas en el comercio exterior a largo plazo.

Al respecto, Penello-Rial (2014) muestra que el efecto negativo de las barreras no arancelarias sobre las exportaciones tiende a ser más fuerte en el caso de los países menos desarrollados:

los Países Menos Adelantados (LDCs por su acrónimo en inglés) de África pero también de África subsahariana se afectan relativamente más que otros, como los de América Latina o del medio-este o norte de África, los cuales verían reducidas sus exportaciones en alrededor del $3 \%$ por cada medida sanitaria o fitosanitaria (SPS por su acrónimo en inglés) sobre productos agrícolas. (2014, p. 13) 10

10 Traducción propia. 
Lo anterior implica que el resultado de la aplicación de políticas comerciales en contextos de integración asimétricos ha tendido a beneficiar en mayor medida a las economías avanzadas, debido a que sus industrias y empresas ostentan niveles de avance tecnológico y de apoyo en I $+\mathrm{D}$ de sus gobiernos que les permite ser mucho más competitivas $\mathrm{y}$, en consecuencia, obtener mayores ganancias relativas en el juego del comercio mundial.

En segundo lugar, a pesar de que la globalización ha sido una condición necesaria (mas no suficiente) para el despegue de las economías emergentes, es importante reconocer que también ha llevado a que mucha gente, especialmente en los países menos desarrollados, sea afectada negativamente al no estar apoyada por programas de seguridad social y a la vez tener bajos niveles de escolaridad. Así, una de las consecuencias menos populares, pero no por ello menos importante de la globalización, es que los mercados globales han llevado a la marginación de muchas personas de los circuitos globales del capital (Soros, 2002; Beck, 2008), dando como resultado más miseria y desigualdad en diversos contextos sociales y laborales a nivel internacional. El resultado de todo esto es "una mayor polarización entre la opulencia y la pobreza a escala global" (Romero \& Vera-Colina, 2012, p. 69).
Este proceso de polarización a escala global se explica en parte por la formación de nuevas clases transnacionales articuladas a las dinámicas globales del capital. Esto no solo ha llevado a la emergencia de una élite transnacional, sino también a que en muchos países ciertas clases preexistentes de campesinos y artesanos tiendan a desaparecer y a ser reemplazadas por nuevas clases trabajadoras urbanas y rurales y nuevos proletarios articulados a las dinámicas económicas globales (Robinson, 2011). Como sugiere este autor, el resultado de estos procesos es "la aparición de una masa de supernumerarios o marginados en expansión" (2011, p. 355).

No obstante, como resalta Beck (2008) retomando a Zygmunt Bauman (2010), mientras los ricos propietarios del capital poseen la capacidad para movilizarse fácilmente alrededor del globo, los pobres asalariados tienden a estar localizados y atados a zonas geográficas concretas del planeta (Beck, 2008) -aun cuando también se articulan a las dinámicas del capital transnacional-. De ahí que, según este autor, la globalización va de la mano de la localización, es decir de la ejecución y consolidación de una serie de actividades a nivel local. De esta forma, ambos procesos - globalización y localización- son "dos caras de la misma moneda": "son al mismo tiempo fuerzas impulsoras y formas de expresión de una nueva polarización y estratificación de la población mundial en ricos globalizados y pobres locali- 
zados (Beck, 2008, p. 118)11". Así, los procesos de globalización y localización interconectados, lo que Robertson (1992) denomina glocalización ${ }^{12}$, dan como resultado

un nuevo reparto de, a la vez, privilegios y ausencia de derechos, riqueza y pobreza, posibilidades de triunfo y falta de perspectivas, poder e impotencia, libertad y falta de libertad. Podríamos decir que la glocalización es un proceso de nueva estratificación a nivel mundial, en cuyo devenir se construye una nueva jerarquía a nivel mundial sociocultural y autorreproductora. (Robertson, 1992)13

En efecto, a pesar de lo planteado atrás en el acápite denominado "Algunos procesos virtuosos en la globalización", hay pruebas de que durante las últimas décadas, al tiempo que existe un vertiginoso crecimiento del comercio mundial, persisten altos niveles de desigualdad y, además, se ha incrementado la desigualdad en el interior de los países (Lakner \& Milanovic, 2013, 2015; Bourguignon, 2015). Aunque alguna evidencia -como se expuso antes- sugiere que la desigualdad internacional no ponderada y la desigualdad internacional ponderada por la población han mejorado durante las últimas décadas, Lakner y Milanovic $(2013$, 2015) revelaron que en realidad la desigualdad del ingreso se mantuvo en niveles altos durante el periodo (1988-2008). Para ello, los autores se concentraron en un concepto diferente de la desigualdad del ingreso que resulta más apropiado para captar el verdadero nivel de desigualdad del ingreso entre las personas de todo el mundo: la desigualdad interpersonal global, que incorpora en el cálculo la desigualdad de las personas dentro de los países. Como estos autores explican, este concepto "capta la desigualdad de los ingresos individuales en el mundo dando a todos sus propios ingresos" (Lakner \& Milanovic, 2015, p. 75).

Lakner y Milanovic $(2013,2015)$ encontraron que la desigualdad interpersonal global se mantuvo alta, con un coeficiente de Gini de alrededor del $70 \%$. Ellos afirman que, si bien la desigualdad parece haber bajado durante la primera década del siglo XXI, estos cambios probablemente no son robustos debido a la presencia de errores en la medición de los ingresos de los individuos pertenecientes al decil de ingresos más alto (Lakner \& Milanovic, 2013, 2015). Los errores de medición son evidentes por dos problemas detectados: la brecha creciente que existe entre los niveles de consumo familiar per cápita en Cuentas Nacionales y los valores medios de consumo o ingreso reportados en las encuestas de hogares (Lakner \& Milanovic, 2013, 2015). En segundo lugar, y lo que es otra manifestación del mismo problema, la información tributaria revela que las encuestas de

11 Cursivas del autor.

12 Neologismo propuesto por Robertson (1992) como una síntesis verbal entre "globalización" y "localización”.

13 Cursivas del autor. 
hogares tradicionales tienden a subestimar los ingresos más altos de la población (Lakner \& Milanovic, 2013, 2015; Atkinson \& Piketty, 2007, 2010). Corrigiendo estos errores mediante un ajuste de los niveles de ingreso que corresponden a los individuos con el $10 \%$ de ingresos más altos, y suponiendo que los ingresos más altos siguen una distribución de Pareto, los autores encuentran un coeficiente de Gini 5 puntos porcentuales más alto.

Por lo tanto, en realidad la desigualdad del ingreso no parece haber bajado durante el periodo 1988-2008. En sus propias palabras:

Global inequality, measured by the Gini index, might not have gone down at all if the entire (or most) of missing income comes from the underestimation of incomes at the top of national income distributions. This important issue obviously requires more research but it highlights the possible global effects of misreporting among the top that have been already noticed in individual countries. (Lakner \& Milanovic, 2013, p. 48)

Por su parte, Bourguignon (2015) muestra detalladamente que la desigualdad en el interior de los países creció durante el periodo 1990-2010, y especialmente desde el año 2000. Este autor descompone el coeficiente de desigualdad de Theil en un componente que describe la desigualdad entre los países (suponiendo que todos los ciudadanos de cada país poseen el mismo ingreso) y otro componente que captura la desigualdad media que existe dentro de los países; este último expresa la desigualdad que se observaría si los ingresos medios de los países fuesen igualados entre sí. Al respecto revela que mientras el componente del índice de Theil que capta la desigualdad entre los países pasó de 0,734 en 1990 a un valor de 0,479 en 2010, el componente del mismo índice que capta la desigualdad en el interior de los países pasó de 0,215 a 0,244 en 2010 (Bourguignon, 2015, p. 43)14. Adicionalmente, este autor advierte que debido a la subrepresentación de los ingresos más altos en la encuestas de hogares, en general puede haber una sobreestimación de la desigualdad entre países, y al mismo tiempo, una subestimación de la desigualdad en su interior; además, si no se normalizan los ingresos por los niveles de PIB per cápita, en términos generales los niveles de desigualdad se incrementan aunque exhiben tendencias similares en el tiempo a las de las mediciones cuando se reescalan los datos por el PIB per cápita (Bourguignon, 2015).

Los resultados generales de estos autores van en la misma dirección que los hallazgos de Piketty (2014) sobre la dinámica distributiva de la riqueza durante las últimas décadas. Piketty

14 Ver Tabla 1 de Bourguignon (2015), en donde se exponen indicadores de desigualdad del ingreso mundial midiendo esta a partir de los ingresos (o gastos en consumo) per cápita en PPA (en dólares del año 2005) reportados en encuestas de hogares reescalando los datos por el PIB per cápita. 
recalca que las fuerzas divergentes que gobiernan este proceso son más poderosas que las fuerzas convergentes presentes en él. En sus propias palabras:

The crucial fact is that no matter how potent a force the diffusion of knowledge and skills may be, especially in promoting convergence between countries, it can nevertheless be thwarted and overwhelmed by powerful forces pushing in the opposite direction, toward greater inequality. It is obvious that lack of adequate investment in training can exclude entire social groups from the benefits of economic growth. Growth can harm some groups while benefiting others (witness the recent displacement of workers in the more advanced economies by workers in China). In short, the principal force for convergence -the diffusion of knowledge- is only partly natural and spontaneous. It also depends in large part on educational policies, access to training and to the acquisition of appropriate skills, and associated institutions. (Piketty, 2014, p. 22)

Piketty argumenta que si la tasa de retorno del capital es significativamente mayor que la tasa de crecimiento de la economía - como fue la constante durante la segunda mitad el siglo XIX, de nuevo durante las últimas décadas del siglo XX y también como ha sucedido hasta ahora durante el siglo XXI- la riqueza heredada tiende a crecer a un mayor ritmo que la producción y el ingreso, para dar lugar a una concentración creciente y extremadamente alta del capital en muy pocas manos alrededor de todo el mundo. El problema es que esta tendencia se refuerza constantemente por la influencia de varios mecanismos, entre ellos que las tasas de ahorro tienden a crecer de forma aguda en función de la riqueza, y la influencia del principio ricardiano de escasez que mantiene altos los precios de recursos estratégicos como los bienes raíces y el petróleo, y contribuye a una mayor divergencia estructural (Piketty, 2014).

El resultado de todo esto es que la concentración del capital alcanza niveles extremadamente altos "potencialmente incompatibles con los valores meritocráticos y los principios de justifica social fundamentales para las sociedades democráticas modernas" (Piketty, 2014, p. 26)15.

La Figura 6 corrobora que la desigualdad a nivel de países y su media por regiones ${ }^{16}$ ha tenido una tendencia creciente para África, Europa y Norteamérica. En el caso de Asia, aunque la tendencia de

15 La traducción es propia.

16 Se seleccionaron los siguientes países por regiones, teniendo en cuenta que tenían la mayor cantidad de datos que permitieran construir series temporales más completas. América Latina: Brasil, Chile, Colombia, Costa Rica, Ecuador, Panamá, Perú y Uruguay. África: Camerún, Irán, Israel, Jordania, Malta, Mauricio, Marruecos, Senegal, Sur África, Egipto. Asia: Albania, Azerbaiyán, Sri Lanka, Hong Kong, India, Indonesia, Japón, Corea del Sur, China, Malasia, Filipinas, Singapur, Tonga, Turquía, República de Macedonia. Europa: Austria, Bélgica, Bulgaria, Croacia, Chipre, Dinamarca, Finlandia, Francia, Alemania, Grecia, Hungría, Irlanda, Italia, Letonia, Lituania, Luxemburgo, Holanda, Noruega, Rumania, República Eslovaquia, Eslovenia, España, Ucrania, Reino Unido. Norteamérica: Canadá, Estados Unidos. 
la desigualdad por ingresos fue decreciente desde mediados de la década del 2000, durante la última década observada esta se mantuvo más alta que durante los años noventa. Solamente para América Latina se presentó una tendencia decreciente en la desigualdad por ingresos; aunque esta región y África se han mantenido como las dos más desiguales del planeta, a pesar del notorio descenso de la desigualdad en la primera durante las últimas dos décadas.
La tendencia del índice de Gini para todo el globo (línea amarilla en la Figura 6) exhibe una tendencia suavemente creciente durante la mayor parte del periodo examinado, lo que corrobora los argumentos planteados. Este indicador pasó de un nivel de 39.9 en el año 1990 a un valor de 43.2 en el año 2018. No obstante, como puede notarse en la misma gráfica, la tendencia creciente fue mucho más marcada durante los años noventa.

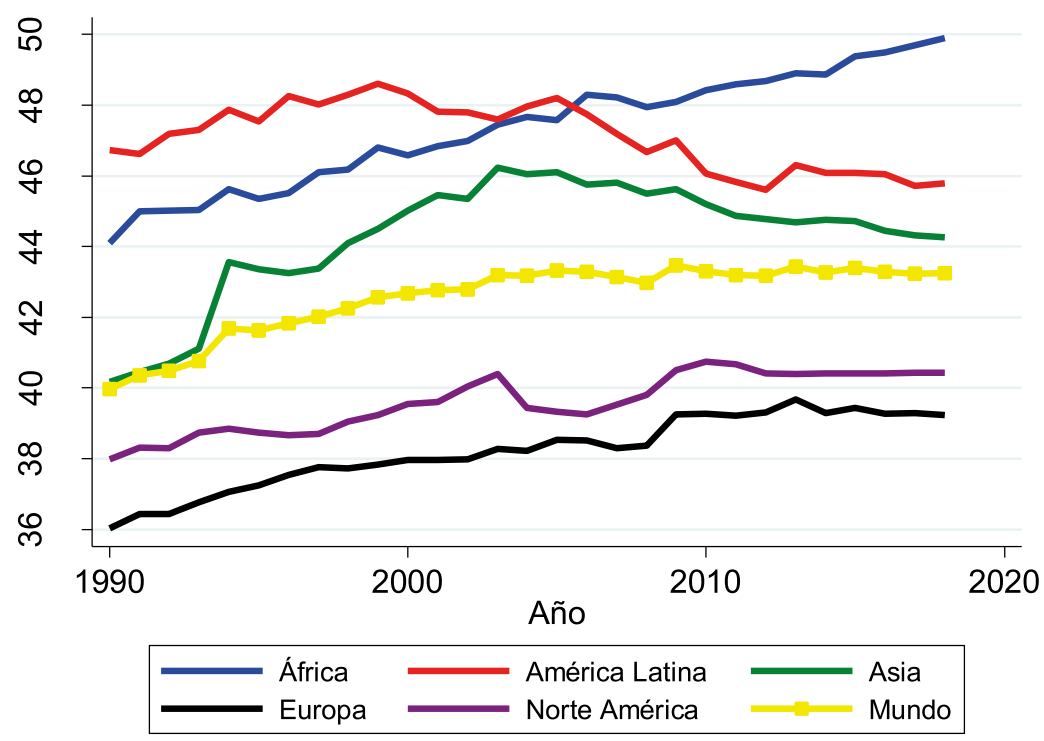

Figura 6. Índice de desigualdad de GINI'17 por región geográfica entre 1990 y 2018.

Fuente: cálculos propios con base en el proyecto de desigualdad de la Universidad de Texas (University of Texas Inequality Project).

$\overline{17}$ Este índice muestra los niveles de desigualdad de ingresos de los hogares. Se deriva de una relación econométrica entre los datos de la base UTIP-UNIDO (basada en las medidas de desigualdad de los pagos o salarios en la industria manufacturera), los datos de Deininger y Squire (1996) y otras variables condicionales. En la página web http://utip.gov.utexas.edu/datasets.html se podrá encontrar más información al respecto. 
La persistencia de altos niveles de desigualdad interpersonal global del ingreso y el incremento de la desigualdad en el interior de los países, fenómenos examinados por Lakner y Milanovic $(2013,2015)$ y Bourguignon (2015), también son consistentes con la hipótesis de Robinson (2011) sobre la consolidación del capitalismo global y la emergencia de una élite transnacional. Su expresión en términos del sistema mundial de intercambio de mercancías es que la sociedad global tiende cada vez a estar menos estratificada con relación a condiciones nacionales y territoriales y más en términos de clases $\mathrm{y}$ relaciones sociales transnacionales (Robinson, 2011).

Sin embargo, la emergencia de los "nuevos procesos globalizadores" como fuerzas cada vez más determinantes, no excluye ni se contrapone a los efectos de las diferencias estructurales y procesos de desarrollo disímiles entre las naciones y los continentes; al contrario, ambas fuerzas se superponen y se retroalimentan entre sí: ahora articuladas a los circuitos globales del capital, las economías menos avanzadas en determinadas zonas geográficas del mundo están condenadas a formar parte de cadenas de suministro y mercados globales, en donde no tienen otra opción que perpetuar sus actividades económicas tradicionales para poder sobrevivir. El resultado inequívoco es la condena de muchas regiones, por ejemplo, aquellas dedicadas a actividades extractivas o con poco avance tecnológico, al atraso sostenido y a la imposibilidad de salir de trampas de pobreza.

Un cuarto punto relevante se deprende de la última idea y gira en torno a la siguiente pregunta: ¿qué explica el impacto diferenciado que ha tenido la globalización durante las últimas décadas sobre el desarrollo de las naciones y la distribución del ingreso? Es evidente que a los procesos de globalización e integración económica subyace una serie de dinámicas del capital inherentes a la evolución del sistema capitalista global. Las transformaciones estructurales de las economías hacen parte de estas dinámicas a largo plazo del capitalismo: tanto los procesos de industrialización como los de terciarización por los que ha atravesado buena parte de las economías del mundo han marcado las claves de la evolución y el progreso social de muchas sociedades desde finales del siglo XIX (Timmer \& Akkus, 2008). Pero, como advierte Losch (2010) de manera aguda, el problema de fondo es que en el mundo contemporáneo no todos los países o lugares ni sus habitantes comparten la misma fase en el proceso de transformación estructural e histórica que caracteriza la evolución de las economías y las sociedades. De modo que se desenvuelven procesos de transformación estructural diferenciados que han jalonado enormes brechas de productividad y competitividad entre los países y las regiones del globo (Losch, 2010). 
La existencia simultánea de procesos de transformación estructural diferenciados refuerza la idea de que la globalización se ha consolidado al tiempo que se han configurado, como contraparte, una serie de procesos de localización alrededor del globo: de eslabones específicos de diversas cadenas productivas, de economías extractivas al servicio de corporaciones multinacionales, de poblaciones enteras dedicadas a actividades económicas asalariadas con bajos niveles de remuneración, de explotación acelerada de recursos naturales, etc. Al respecto, la visión de Beck (2008) todavía hoy en día resulta sugestiva. Según este autor, las empresas "globales" deben desarrollar relaciones locales por dos razones diferentes:

[...] en primer lugar, su producción se apoya sobre unos pilares locales $\mathrm{y}$, en segundo lugar, porque hay que 'retirar de la circulación' símbolos globalmente comercializables de culturas locales, que precisamente por eso permanecen vivas, eruptivas y dispares. 'Global' significa, traducido y 'conectado a tierra', 'en muchos lugares a la vez' y, por lo tanto, es sinónimo de translocal. (Beck, 2008, p. 101)18

Lo anterior también lleva a pensar que la consolidación de los circuitos globales de capital y mercancías desarrollados durante las últimas décadas $\mathrm{y}$, como consecuencia de ello, la emergencia de nuevas clases transnacionales, en realidad son el resultado de la influencia económica y política de grupos y círculos de poder de alcance mundial, que, en su gran mayoría, tienen su origen político y económico en las naciones económicamente avanzadas y además funcionan en conexión estrecha a ellas.

En quinto lugar y como consecuencia de lo anterior, la profundización de los procesos de especialización según las ventajas comparativas a nivel internacional ha llevado a que los países con menores niveles de avance tecnológico se especialicen en mayor medida en actividades intensivas en recursos naturales, lo que, a medida que se dan los cambios demográficos, tiende a activar círculos viciosos de pobreza, desigualdad y deterioro del medio ambiente a largo plazo. Losch (2010) lo plantea de manera precisa:

Estas circunstancias específicas en las que las economías y las sociedades deben enfrentar simultáneamente sus transiciones económicas y demográficas en el contexto de la globalización y bajo la restricción de cada vez mayor escasez de recursos (y costo a su acceso) son absolutamente nuevas y únicas en la historia mundial. Adicionalmente, las migraciones internacionales masivas ya no constituyen más una alternativa de escape, siendo los mercados laborales la gran excepción a los procesos de liberación globales. (Losch, 2010, p. 205)19. 
Este proceso tiene tres implicaciones importantes: en primer lugar, en los países menos avanzados tecnológicamente y con abundancia relativa de recursos naturales y mano de obra no calificada, persiste la especialización productiva en sectores económicos poco dinámicos y con menores niveles de diversificación productiva, mientras en los países industrializados con abundancia relativa de mano de obra calificada y conocimiento, las economías se especializan en mayor medida en sectores dinámicos generadores de externalidades positivas y diversificación productiva. La consecuencia a largo plazo es conocida: mientras los primeros exhiben en el nivel agregado productividades marginales decrecientes en el tiempo, los segundos mantienen tasas de crecimiento económico sostenido y círculos virtuosos de innovación tecnológica. Desde hace varias décadas la teoría del crecimiento endógeno ha dado explicaciones contundentes de este fenómeno, a partir del análisis del papel desempeñado por factores como la generación y difusión del conocimiento (Romer, 1986), la presencia de ventajas comparativas dinámicas y los procesos de aprendizaje en la práctica (learning by doing) (Lucas, 1988; Matsuyama, 1992), la diversificación productiva (Grossman \& Helpman, 1991), la inversión del gasto público en infraestructura (Barro, 1990) entre otros, todos los cuales se retroalimentan y complementan entre sí.
En segundo lugar, la mayor especialización en bienes intensivos en recursos naturales conduce a que los ingresos externos de los países tiendan a estar concentrados en una menor cantidad de productos y destinos de exportación, lo que genera una mayor vulnerabilidad frente a choques externos. En efecto, los países exportadores de commodities se suelen afectar más intensamente cuando los precios internacionales de dichos bienes se desploman (Grigoli et al., 2017; Garavito-Acosta et al., 2019), lo que tiene consecuencias negativas sobre su crecimiento económico, tanto a corto como a largo plazo (Grigoli et al., 2017; Mendoza, 1995, entre otros).

En tercer lugar, la especialización de las economías menos avanzadas en sectores intensivos en recursos naturales ha llevado a su reprimarización a lo largo de las últimas décadas. En el caso particular de América Latina y la mayoría de los países de África Subsahariana, los procesos de apertura económica de la mano de un crecimiento vertiginoso de la inversión extranjera directa (IED) han reproducido la inserción dependiente en la división internacional del trabajo de sus países con base en el desarrollo de economías extractivas. Esto ha tenido y probablemente seguirá teniendo -en caso de perpetuarse estas interrelaciones económicas-consecuencias desastrosas sobre el medio ambiente y, por ende, sobre las sociedades de estos países. 
En el caso de América Latina (Figura 7), la mayor parte de IED, excluyendo a Brasil, durante la primera década del presente siglo se concentró en el sector de recursos naturales, con un $51 \%$ respecto al total de IED -la participación más alta en el año 2012-, al tiempo que una fracción menor correspondió a inversiones de servicios (37\%) y una proporción mucho menor a inversiones en el sector manufacturero (12\%). Esta composición sectorial hasta el año 2012 se presentó por el auge de los precios de las materias primas que arrancó, aproximadamente, en el año 2000 con los precios crecientes del petróleo y los metales, fruto de las demandas de economías emergentes como China e India.
Por su parte, como aduce Belloni (2013), estos procesos han estado liderados por la actividad de multinacionales que operan bajo una lógica neoextractivista que comporta graves consecuencias sobre el medio ambiente y, en consecuencia, compromete la sostenibilidad de las sociedades. El resultado de la consolidación del neoextractivismo es la configuración de procesos de intercambio ecológicamente desiguales en los países suramericanos. Y es que, a pesar de la recomposición de la IED sectorial durante varios años, la extracción de recursos naturales sigue teniendo una importante participación; la Figura 7 exhibe una tendencia creciente para los últimos años: del $22 \%$ en 2017 al $42 \%$ en 2018.

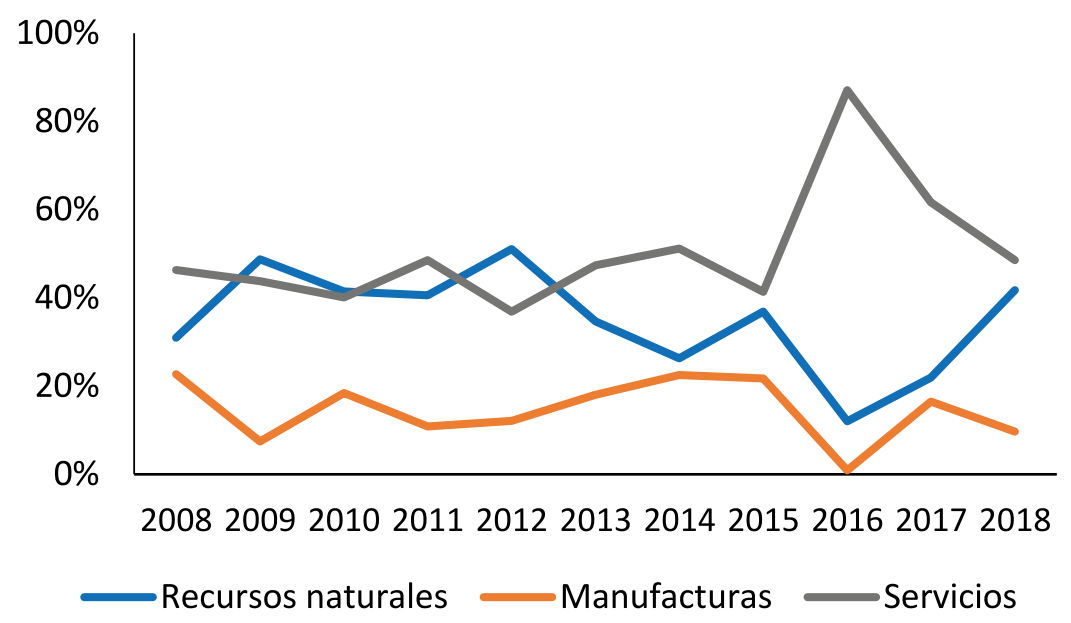

Figura 7. Inversión extranjera directa por sector económico para América del Sur excluyendo Brasil.

Fuente: cálculos propios con base en datos de la CEPAL (2012). Se incluyen países que reportan la IED por sector económico. 


\section{CONCLUSIONES}

Desde comienzos de los años setenta empezaron a gestarse una serie de cambios en el sistema capitalista que transfiguraron las relaciones sociales de producción y las relaciones de poder entre los capitalistas y los asalariados al igual que las fuerzas productivas a nivel internacional. Estas transformaciones fueron originadas por la crisis estructural de los años setenta, la cual jalonó una baja progresiva en la tasa ganancia (Harvey, 2007; Duménil \& Lévy, 2007; Belloni, 2013). Esta crisis precipitó una serie de reacciones estratégicas de la clase dirigente capitalista en las grandes potencias económicas, que impulsó una transformación hasta entonces inédita en las reglas de política económica y dio lugar a una nueva fase de expansión del capitalismo a escala mundial (Duménil \& Lévy, 2007).

Esta fase es la globalización neoliberal, una era en la que se han desarrollado diversos procesos virtuosos que han sido fuente de prosperidad para muchas economías. Pero la globalización también ha deparado graves problemas económicos y sociales para inmensas comunidades y diversos sectores alrededor del globo. Hay pruebas de que el crecimiento del comercio mundial ha ido de la mano de la persistencia de altos niveles de desigualdad interpersonal global del ingreso durante las últimas décadas, con incrementos en el componente de la desigualdad en el interior de los países, especialmente durante el periodo 1990-2010. Los trabajos amplios recientes en el ámbito de la desigualdad, en particular los de Lakner y Milanovic (2013, 2015) y Bourguignon (2015), apuntan hacia allá.

Lejos de ser homogénea, la globalización neoliberal dio lugar a un sistema global con polos antagónicos, pero dialécticamente interdependientes, en donde, por una parte, la clase capitalista global despliega sus acciones extraterritorialmente -incluyendo sus centros de producción de valores, significados (Pérez, 2018), retóricas y verdades-; $\mathrm{y}$, por otra parte, se reproduce una población creciente de asalariados y otros grupos sociales subordinados. Como Pérez (2018) señala agudamente, mientras los primeros actúan como los emisores universales que determinan la mayor parte de los patrones de consumo (y cosmovisiones), los segundos lo hacen como receptores territorializados.

El resultado de esta dinámica ha sido la perpetuación de diversos tipos de desigualdades y la permanencia de un gran conjunto de grupos sociales sumidos en la pobreza y atados a territorios generalmente explotados por las garras del capital transnacional, cuyos discursos y cosmovisiones propias terminan siendo invisibilizados por los emisores que se autoproclaman como universales.

Pero ¿qué tan viable es la globalización neoliberal en el futuro cercano? La progresiva desaceleración económica que 
se viene presentado en todo el mundo desde la gran recesión, así como la grave crisis económica y social que se ha desatado recientemente con la llegada del SARS-CoV-2, son señales inequívocas de una nueva crisis estructural del sistema capitalista y del colapso de la globalización neoliberal. Pero esto será materia de próximos trabajos.

\section{AGRADECIMIENTOS}

Agradecemos a nuestros estudiantes de Comercio Internacional y Macroeconomía, por las preguntas y discusiones generadas en el salón de clase sobre los temas de la investigación desde hace varios años, las cuales inspiraron el desarrollo y, sobre todo, la necesidad intelectual del artículo. También agradecemos los comentarios de los dos evaluadores anónimos del artículo, así como las sugerencias y críticas de otros lectores de versiones anteriores del documento.

\section{FINANCIAMIENTO}

La versión inicial de este artículo contó con el apoyo de la Facultad de Ciencias Sociales y Económicas de la Universidad del Valle y el Centro de Investigaciones y Documentación Socioeconómica (CIDSE), como un producto del proyecto de investigación de presentación interna titulado «¿Qué tanta evidencia existe a favor de la teoría neoclásica del comercio internacional? El caso de las economías latinoamericanas».

\section{DECLARACIÓN DE CONFLICTOS DE INTERESES}

Los autores declaran que no existe conflicto de intereses.

\section{CONTRIBUCIÓN DE LOS AUTORES}

El trabajo es el resultado del trabajo en equipo de los dos autores. 


\section{REFERENCIAS}

[1] Anand, S., \& P. Segal. (2008). What Do We Know about Global Income Inequality? Journal of Economic Literature, 46(1), 57-94. https://doi.org/10.1257/jel.46.1.57

[2] Atkinson, A. B. \& T. Piketty (2007). Top Incomes Over the Twentieth Century: A Contrast Between Continental European and English-Speaking Countries. Oxford University Press.

[3] Atkinson, A. B. \& T. Piketty (2010). Top Incomes: A Global Perspective. Oxford University Press. https://doi.org/10.1086/261726

[4] Bauman, Z. (2010). La globalización. Consecuencias humanas (5.a reimp.). Fondo de Cultura Económica.

[5] Beck, U. (2008). ¿Qué es la globalización? Bolsillo Paidós.

[6] Belloni, P. (2013). Inserción externa, capitales transnacionales e intercambio ecológicamente desigual en la América del Sur posneoliberal. Sociedad y Economía, 25, 15-38.

[7] Bourguignon, F. (2011). A turning Point in Global Inequality... And Beyond. In Annual Bank Conference on Development Economics, Papers and Proceedings. http://siteresources.worldbank.org/EXTABCDE/Resources/7455676-129252845 6380/7626791-1303141641402/7878676-1306270833789/Parallel-Session-6-Fran cois_Bourguignon.pdf.

[8] Bourguignon, F. (2015). The Globalization if Inequality. Princeton University Press. https://doi.org/10.1515/9781400865659

[9] CEPAL. (2012). La inversión extranjera directa en América Latina y el Caribe. Unidad de Inversiones y Estrategias Empresariales de la División de Desarrollo Productivo y Empresarial, CEPAL.

[10] Deininger, K. \& Squire, L. (1996). A New Data Set Measuring Income Inequality. The World Bank Economic Review, 10(3), 565-591. https://oi.org/10.1093/ wber/10.3.565

[11] Duménil, G. \& Lévy, D. (2007). Crisis y salida de la crisis. Orden y desorden neoliberales. Fondo de Cultura Económica. 
[12] Fontagné, L. \& Freudenberg, M. (1997). Intra-Industry Trade: Methodological Issues Reconsidered. CEPII Documento de Trabajo, (97-01). http://www.cepii.fr/ PDF_PUB/wp/1997/wp1997-01.pdf

[13] Garavito-Acosta, A. L., Montes-Uribe, E., Toro-Córdoba, J. H., Agudelo-Rivera, C., Alfonso-Corredor, V. A., Carmona-Duarte, Á., ... \& Zárate-Solano, H. M. (2020, jul.). Ingresos externos corrientes de Colombia: desempeño exportador, avances y retos. Revista Ensayos sobre Política Económica, 95, 1-81. https://doi. org/10.32468/espe. 95

[14] Garay, L.J., Barberi, F. \& Cardona, I. M. (2006). La negociación agropecuaria en el TLC. Alcances y consecuencias. Planeta Paz.

[15] Grigoli, F., Herman, A. \& Swiston, M. A. J. (2017). A Crude Shock: Explaining the Impact of the 2014-16 Oil Price Decline Across Exporters. International Monetary Fund. https://doi.org/10.5089/9781484310175.001

[16] Grossman, G. \& Helpman, E. (1991). Innovation and Growth in the Global Economy. The MIT Press.

[17] Harrison, A., McLaren, J. \& McMillan M. (2011). Recent Perspectives on Trade and Inequality. The Annual Review of Economics, 3, 261-89. https://doi.org/10.1146/ annurev.economics.102308.124451

[18] Harvey, D. (2007). Breve historia del neoliberalismo. Ediciones AKAL.

[19] Harvey, D. (2008). La condición de la posmodernidad: investigación sobre los orígenes del cambio cultural. Amorrortu.

[20] Helpman, E., Itskhoki, O., Muendler, M. \& Redding, S. (2017). Trade and Inequality: From Theory to Estimation. Review of Economic Studies, 84(1), 357-405. https:// doi.org/10.1093/restud/rdw025

[21] Hernández, E. A. (2017). Comercio intraindustrial y costos de ajuste para la industria colombiana (1991-2015). (Tesis para optar al título de Maestría en Economía Aplicada), Universidad del Valle, Colombia.

[22] Hernández, E. \& Raffo, L. (2019). Comercio intraindustrial y variaciones del empleo en la industria colombiana, 1991-2015. Revista Semestre Económico, 22(53), 21-51. https://doi.org/10.22395/seec.v22n53a2 
[23] Keynes, J. M. (1973). The General Theory of Employment, Interest and Money. In The Collected Writings of John Maynard Keynes: Vol. VII. Macmillan and the Cambridge University Press.

[24] Krugman, P. (1979). Increasing Returns, Monopolistic Competition, and International Trade. Journal of International Economics, 9(4), 469-479. https://doi. org/10.1016/0022-1996(79)90017-5

[25] Krugman, P. (1981). Scale Economics, Product Differentiation, and the Pattern of Trade. American Economic Review, 70, 950-959. https://doi. org/10.1596/1813-9450-6719

[26] Lakner, C. \& Milanovic, B. (2013). Global Income Distribution: From the Fall of the Berlin Wall to the Great Recession. In The World Bank Policy Research Working Paper, n. ${ }^{\circ}$ 6719. The World Bank, Development Research Group, Poverty and Inequality Team.

[27] Lakner, C. \& Milanovic, B. (2015). La distribución global del ingreso de la caída del Muro de Berlín a la gran recesión. Revista de Economía Institucional, 17(32), 71-128. https://doi.org/10.18601/01245996.v17n32.03

[28] Losch, B. (2010). Beyond Trade: Economic Transition in the Globalization Era and Prospects for Poverty and Environment. In J. Cook et al. (eds.), Vulnerable Places, Vulnerable People: Trade Liberalization, Rural Poverty and the Environment (pp. 198-209). The World Bank, WWF and Edward Elgar. https://doi. org/10.1016/0304-3932(88)90168-7

[29] Malinowitz, S. S. (2010). Obamaismo: la fase superior de la financiarización. En Jairo Estrada (comp.), El impacto de la crisis: tendencias y perspectivas del capitalismo contemporáneo (pp. 111-123). Universidad Nacional de Colombia.

[30] Matsuyama, K. (1992). Agricultural Productivity, Comparative Advantage and Economic Growth. Journal of Economic Theory, 58, 317-334. https://doi. org/10.1016/0022-0531(92)90057-O

[31] Mendoza, E. G. (1995). The Terms of Trade, the Real Exchange Rate, and Economic Fluctuations. International Economic Review, 101-137. https:/doi. org $/ 10.2307 / 2527429$

[32] Meschi, E. \& Vivarelli, M. (2009). Trade and Income Inequality in Developing Countries. World Development, 37(2), 287-302. https://doi.org/10.1016/j. worlddev.2008.06.002 
[33] Milanovic, B. (2005). Worlds Apart: Measuring International and Global Inequality. Princeton University Press.

[34] Mishra, S., Lundström, S., \& Anand, R. (2011). Service Export Sophistication and Economic Growth. World Bank Policy Research Working Paper, (5606). https:// doi.org/10.1596/1813-9450-5606

[35] Moreno, A. \& Posada, H. (2007). Evolución del comercio intraindustrial entre las regiones colombianas y la Comunidad Andina, 1990-2004: un análisis comparativo. Lecturas de Economía, 66, 83-118.

[36] OMC. (2010). Informe Mundial del Comercio, 2010. OMC.

[37] OMC. (2011). Informe Mundial del Comercio, 2011. OMC.

[38] OMC. (2013). Informe Mundial del Comercio, 2013. OMC.

[39] OMC. (2014). Informe Mundial del Comercio, 2014. OMC.

[40] Paul, J. R. (2006). ¿Es realmente libre el libre comercio? Siglo del Hombre Editores, Universidad de los Andes y la Pontificia Universidad Javeriana.

[41] Penello-Rial, D. (2014). Study of Average Effects of non-tariff Measures on Trade Imports. UN. https://doi.org/10.15366/bp2018.18.012

[42] Pérez, J. M. (2018). Más acá del consumo: glocalización. Bajo Palabra. II Época, 18, 255-270.

[43] Pérez-Rincón, M. A. (2007). El intercambio ecológicamente desigual del comercio internacional colombiano. Ecología Política, 33, 121-123.

[44] Piketty, T. (2014). Capital in the Twenty-First Century. Harvard University Press. https://oi.org/10.4159/9780674369542

[45] Preciado, P. B. (2020). Aprendiendo del virus. En P. Amadeo (ed.), Sopa de Wuhan, pensamiento contemporáneo en tiempos de pandemias. Editorial ASPO.

[46] Ravallion, M. (2018). Inequality and Globalization: A Review Essay. Journal of Economic Literature, 56(2), 620-642. https://doi.org/10.1257/jel.20171419

[47] Riad, N., Errico, M. L., Henn, C., Saborowski, C., Saito, M. \& Turunen, M. J. (2012). Changing Patterns of Global Trade. International Monetary Fund. 
[48] Robertson, R. (1992). Globalization: Social Theory and Global Culture. Sage.ao https://doi.org/10.1177/0896920511411592

[49] Romer, P. (1986). Increasing Returns and Long-Run Growth. Journal of Political Economy, 94, 1002-1037. https://doi.org/10.1086/261420

[50] Romero, A. \& Vera-Colina, M. A. (2012). La globalización posible: límites y alternativas. Cuadernos de Economía, 31(58), 49-76.

[51] Smith, A. (1981). An Inquiry into The Nature and Causes of The Wealth of Nations. In R. H. Campbell \& A. S. Skinner (eds.), The Glasgow Edition of the Works of Correspondence of Adam Smith. Liberty Fund, Liberty Classics Indianapolis.

[52] Soros, G. (2002). Globalización. Editorial Planeta Colombiana.

[53] Tamayo, M. P. (2015). El fenómeno del offshoring. Revista Ecos de Economía, 18(38), 157-182. https://doi.org/10.17230/ecos.2014.38.6

[54] Timmer, C. P. \& Akkus, S. (2008). The Structural Transformation as A Pathway Out of Poverty: Analytics, Empirics and Politics. Center for Global Development Working Paper, (150). https://doi.org/10.2139/ssrn.1213154

[55] UNCTAD. (2010). International Trade After the Economic Crisis: Challenges and New Opportunities. ONU. www.unctad.org/en/docs 